\title{
História e memória de vidro: as fotografias brasileiras do eclipse de 1919 em Sobral
}

\author{
History and memory on glass: the Brazilian \\ photographs of the 1919 eclipse in Sobral
}

\section{Renaldo Nicácio da Silva Júnior ${ }^{i}$ \\ 'Analista de Ciência e Tecnologia Observatório Nacional. \\ Rio de Janeiro - RJ - Brasil \\ orcid.org/0000-0003-4311-9581 \\ renaldo@on.br \\ Christina Helena da Motta Barboza ${ }^{i t}$ \\ ii Pesquisadora, Museu de Astronomia e Ciências Afins. \\ Rio de Janeiro - RJ - Brasil orcid.org/0000-0002-5575-5385 christina@mast.br}

Recebido em 21 mar. 2019. Aprovado em 2 jan. 2020.
SILVA JÚNIOR, Renaldo Nicácio da; BARBOZA, Christina Helena da Motta. História e memória de vidro: as fotografias brasileiras do eclipse de 1919 em Sobral. História, Ciências, Saúde - Manguinhos, Rio de Janeiro, v.27, n.3, jul.-set. 2020, p.983-1000.

\section{Resumo}

O objetivo do artigo é divulgar as fotografias astronômicas feitas pela expedição brasileira enviada a Sobral para registrar o eclipse total do Sol de 29 de maio de 1919. Uma rica coleção de fotografias, na maioria inéditas, disponíveis em suporte de placas de vidro, encontra-se na Biblioteca do Observatório Nacional. A fotografia ocupou lugar central na astronomia do século XX. O eclipse de Sobral ganhou repercussão mundial devido à comprovação da teoria da relatividade geral pelas expedições inglesas. Neste texto ressaltamos a participação dos astrônomos do Observatório Nacional no evento, pois foram os primeiros brasileiros a ter sucesso na obtenção de fotografias da coroa solar.

Palavras-chave: eclipse solar; fotografia astronômica; Henrique Morize (1860-1930); negativos de vidro; expedições astronômicas.

\section{Abstract}

The objective of this article is to disseminate the astronomical photographs taken by the Brazilian expedition sent to Sobral (state of Ceará) to record the total eclipse of the Sun on May 29, 1919. There is a rich collection of photographs, most unpublished, available on glass plates stored in the Library of the Observatório Nacional. Photography was central to astronomy in the twentieth century. Thus, while the eclipse in Sobral had worldwide repercussions due to the proof of the theory of general relativity by the English expeditions, in this article we highlight the participation of astronomers from the Observatorio Nacional at the same event, since they were the first Brazilians to successfully obtain photographs of the Sun's corona.

Keywords: solar eclipse; astronomical photographs; Henrique Morize (18601930); glass negatives; astronomical expeditions. 
$\mathrm{N}$ dia 29 de maio de 1919, uma expedição do Observatório Nacional (ON) enviada a Sobral, no interior do Ceará, registrou, em uma série de fotografias astronômicas, o eclipse total do Sol. Trata-se de uma rica coleção de fotografias, a maior parte delas inédita, disponíveis nas placas de vidro em que originalmente foram produzidas e reveladas ou reproduzidas, todas depositadas na Biblioteca do ON. É dessas fotos que este artigo se ocupará. ${ }^{1}$

Não custa lembrar que a expedição inglesa instalada em Sobral para a observação desse mesmo fenômeno obteve suas próprias fotografias, as quais foram utilizadas na comprovação da teoria da relatividade geral de Einstein. O eclipse de Sobral, que em 2019 completou cem anos, ganhou visibilidade pública e atenção especial dos astrônomos e historiadores das ciências principalmente por causa da expedição inglesa. No entanto, a coleção de placas de vidro da expedição do ON tem grande importância científica e histórica, entre outras razões porque foram as primeiras fotografias bem-sucedidas da coroa solar obtidas por astrônomos brasileiros.

\section{A aplicação científica da fotografia na astronomia}

Quase imediatamente após o anúncio da invenção da fotografia, em 1839, e durante todo o século XIX, cientistas de diversas áreas do conhecimento investiram em pesquisas para compreender e se apropriar dessa revolucionária forma de produção de imagens, contribuindo assim para o desenvolvimento de novos materiais, equipamentos e processos fotográficos. A própria origem da fotografia resulta da convergência entre conhecimentos e práticas nos campos da óptica (como a câmara escura) e da química (na busca de substâncias, de um lado sensíveis à luz, e de outro, capazes de revelar e fixar a imagem formada, como o vapor de mercúrio e o cloreto de sódio, empregados por Daguerre) (Peres, 2014; Rouillé, 2009).

Os astrônomos logo perceberam o potencial da nova ferramenta (Lankford, 1984; Thomas, 1998). O astrônomo inglês John Herschel (1792-1871), por exemplo, realizou diversos experimentos com a câmara escura e depois com a fotografia, vários deles em colaboração com William Fox Talbot (1800-1877), contemporâneo de Daguerre e também identificado pela historiografia como inventor da fotografia - ao contrário de Hercule Florence (1804-1879), raramente citado (Turazzi, 2008). Em 1854, Herschel encomendou a Warren De la Rue (1815-1889) o projeto de um instrumento capaz de fotografar o Sol, o qual resultaria no desenvolvimento do chamado "foto-heliógrafo", instalado no Observatório de Kew e utilizado em um programa de monitoramento das manchas solares.

Entre os desafios iniciais a vencer para que a fotografia pudesse ser aplicada à astronomia, destacava-se o longo tempo de exposição à luz, que impunha a necessidade de compensar o movimento de rotação da Terra (Thomas, 1998; Peres, 2014). De todo modo, aquela que é considerada a primeira fotografia de um objeto celeste - um daguerreótipo da superfície da Lua - foi obtida já em março de 1840 pelo químico norte-americano John Draper (18111882). No final dessa mesma década, no então recém-criado Observatório de Harvard, William Bond (1789-1859) e George Philips Bond (1825-1865), respectivamente pai e filho, em colaboração com o fotógrafo John Whipple (1822-1891) e com o auxílio do maior 
telescópio refrator até então instalado, obtiveram uma série de fotografias da Lua bastante nítidas, premiadas na Exposição Universal de Londres em 1851.

O Sol foi outro corpo celeste que logo atraiu a atenção dos fotógrafos. E ao longo da segunda metade do século XIX, cada vez mais astrônomos queriam fotografá-lo. Fotografar a coroa solar constituiu um desafio especial até pelo menos o início do século XX. Note-se que apenas durante um eclipse total do Sol, fenômeno periódico, porém visível cada vez em uma estreita faixa da superfície da Terra, a coroa solar podia ser observada e fotografada. Nesse sentido, as dificuldades técnicas que se apresentavam aos astrônomos amadores e profissionais não devem ser desprezadas. Dentre elas destacam-se a duração da totalidade do eclipse, que pode ser muito curta, da ordem de poucos minutos, e a necessidade de transporte, instalação e ajuste dos telescópios, com suas lentes de vidro e seus mecanismos de relojoaria, no campo de observação do eclipse, nem sempre de fácil acesso e com boa infraestrutura (Pang, 2002). Empregando o foto-heliógrafo por ele construído, De la Rue observou o eclipse total do Sol de 18 de julho de 1860 na Espanha. Durante muito tempo consideradas pioneiras, suas fotografias da coroa solar constituem um marco na história da fotografia astronômica.

Outro marco importante na história da aplicação da fotografia à astronomia foi o trânsito de Vênus pelo disco do Sol, em 9 de dezembro de 1874 - como indicativo de que a noção de "progresso" não se aplica a cronologias do desenvolvimento científico de modo inequívoco. Esse fenômeno astronômico, que só ocorre duas vezes a cada século, na época era considerado decisivo para o cálculo da paralaxe solar, utilizada para determinar a distância entre a Terra e o Sol. Para realizar as medições necessárias, vários países optaram pelo uso da fotografia no registro dos contatos entre Vênus e o disco do Sol. No entanto, apesar das muitas expedições astronômicas organizadas, os resultados científicos obtidos com a fotografia foram avaliados como pífios (Lankford, 1984). Em consequência, no congresso internacional organizado para coordenar as observações do trânsito de Vênus seguinte, em 6 de dezembro de 1882, foi decidido que não se utilizaria a fotografia. De fato, apenas os astrônomos norte-americanos o fizeram.

A possibilidade de medição das imagens fotográficas sem dúvida era uma questão central para os astrônomos - assim como para os pesquisadores de outras áreas do conhecimento, como a física, a botânica e a própria medicina. Segundo diversos autores (Daston, Galison, 1992; Daston, 2017; Latour, 2000; Rouillé, 2009), a busca pela quantificação (no caso da fotografia astronômica, expressa não só pela nitidez e profusão de detalhes, mas por tempo de exposição, distância focal e, sobretudo, produção de séries) encontra-se no cerne do surgimento do conceito de "objetividade científica" em meados do século XIX. Igualmente essencial nesse processo histórico foi a convicção, firmada desde então até pelo menos o período entreguerras, de que as mais variadas formas de subjetividade, da admissão do compromisso com dada teoria até a simples mediação do observador, comprometem a "verdade" que deve ser perseguida na produção do conhecimento científico. Nesse sentido, a objetividade científica da segunda metade do século XIX pode ser traduzida como "objetividade mecânica" (Daston, Galison, 1992). Como sintetiza o fotógrafo e historiador da fotografia André Rouillé (2009, p.109), "Funcionando ela própria conforme princípios científicos, a fotografia vai contribuir para modernizar o conhecimento; em particular o saber científico. Modernizar é, essencialmente, abolir qualquer subjetividade 
dos documentos; registrar, sem esquecimento nem interpretação, para autenticar, ou para substituir, o próprio objeto".

Deve ser ressaltado o fato de que a objetividade mecânica, tão bem representada pela adoção da fotografia pelas diversas disciplinas científicas, impôs-se no contexto do desenvolvimento do capitalismo industrial, marcado pela crescente mecanização da produção e por um acentuado processo de urbanização. Tanto quanto as máquinas a vapor, as estradas de ferro e o telégrafo, a fotografia simbolizava a ideologia vigente de "progresso". Não à toa, desde 1851 ocupou lugar de destaque em todas as exposições universais, essas verdadeiras "vitrines do progresso" (Neves, 1986; Rouillé, 2009).

De acordo com a historiografia, um momento de virada na adoção da fotografia pelos astrônomos foi o projeto internacional "Carte du Ciel", proposto em 1887 e coordenado por Ernest Mouchez (1821-1892), então diretor do Observatório de Paris. O projeto, que chegou a reunir 18 observatórios espalhados pelos dois hemisférios, consistia na obtenção de séries de fotografias de partes diferentes da abóbada celeste utilizando um mesmo padrão de telescópio, de modo que se pudesse elaborar um catálogo de estrelas supostamente mais completo e, em simultâneo, construir um mapa de todo o céu (Lankford, 1984; Bigg, 2000). As placas fotográficas eram previamente marcadas com um reticulado de $5 \mathrm{~mm}$, a fim de aumentar a precisão das medidas. A intenção era que o projeto estivesse concluído no final do século XIX, porém ele só foi formalmente encerrado em 1970. Várias razões podem explicar o relativo fracasso, tais como a limitação inicial imposta pelo instrumento-padrão escolhido, que tornou o projeto caro e fez com que alguns países atrasassem os trabalhos ou desistissem do projeto (como o próprio Brasil), o surgimento de novas agendas científicas, as mudanças tecnológicas na astronomia e na fotografia, as turbulências sociais, políticas e econômicas, as guerras. De todo modo, o projeto "Carte du Ciel" deixou um legado de milhares de negativos de vidro e é considerado um marco fundamental não só para a aceitação da fotografia pela astronomia, mas para a cooperação científica internacional.

A consolidação da astrofísica como novo paradigma científico também desempenhou importante papel na aceitação da fotografia pelos astrônomos. O marco inicial na emergência da astrofísica é considerado o ano de 1856, quando Gustav Kirchhoff (18241887) e Robert Bunsen (1811-1899) revelaram a possibilidade de determinar a composição química do Sol por meio de uma análise comparativa do comprimento de onda das riscas, ou raias, visíveis no espectro da luz solar com aquelas produzidas em laboratório por gases aquecidos. Ora, apenas a utilização da fotografia permitia captar e registrar, para estudo posterior, as raias espectrais do Sol e demais corpos celestes. Desde a década de 1880, portanto, a fotografia tornou-se uma ferramenta usada em todos os ramos da astrofísica observacional (Meadows, 1984a).

Segundo alguns autores (Meadows, 1984b; Pang, 2002), as pesquisas em astrofísica impulsionaram de forma decisiva a organização de expedições para a observação de eclipses totais do Sol, já que estes constituíam uma ocasião privilegiada para a obtenção de fotografias desse astro. No período compreendido entre 1850 e 1920, a faixa de totalidade de eclipses do Sol atravessou o território brasileiro em seis ocasiões: 1853, 1858, 1865, 1893, 1912 e 1919. Conforme ressaltou Christina Barboza (2010, p.275), “[à] exceção do primeiro [eclipse, em 1853], para a observação de todos eles foram organizadas expedições 
astronômicas, inclusive por instituições existentes no país, como o Observatório Imperial/ Nacional e o Observatório de São Paulo".

A validade da teoria da relatividade deveria ter sido testada pela primeira vez no eclipse de 1912, que ocorreu em 10 de outubro e foi visível no centro-sul do Brasil (Caffarelli, 1980; Einsensteadt, Videira, 1995; Kennefick, 2009; Barboza, 2010). Em artigo publicado em 1911, o próprio Einstein sugeriu a ideia de testar a teoria (ainda a relatividade restrita) durante um eclipse total, utilizando a fotografia para medir o desvio da luz das estrelas provocado pela atração gravitacional exercida por um corpo de grande massa (no caso, o Sol). A pedido, Charles Perrine (1867-1951), na época diretor do Observatório de Córdoba, assumiu a tarefa de fazer as observações durante o eclipse seguinte, no Brasil. Além dele e da equipe que o acompanhou, porém com objetivos científicos distintos, os observatórios de La Plata, de Greenwich, de Paris e os brasileiros ON e Observatório de São Paulo também enviaram expedições para observar o eclipse na serra da Mantiqueira. A chuva que caiu na região, no entanto, impediu a obtenção de qualquer fotografia do fenômeno.

Após outras tentativas fracassadas, devido ao mau tempo e/ou à guerra, o eclipse total do Sol de 29 de maio de 1919, também visível no Brasil, foi o evento em que a teoria afinal pode ser comprovada (já então como relatividade geral) por um grupo de astrônomos ingleses liderados por Frank Dyson (1868-1939) e Arthur Eddington (1882-1944). Foi o diretor do ON na época, Henrique Morize (1860-1930), quem indicou Sobral, no Ceará, como a cidade que reunia as melhores condições para receber as expedições - não sem antes realizar um levantamento de dados meteorológicos e de infraestrutura de localidades na chamada faixa de totalidade. Duas expedições estrangeiras se dirigiram para a cidade cearense. A inglesa, que visava à comprovação da teoria, era liderada por Charles Davidson (1875-1970) e Andrew Crommelin (1865-1939), ambos do Observatório de Greenwich. Para evitar o fracasso nas observações por mau tempo, outra expedição inglesa, comandada por Arthur Eddington e Edwin Cottingham (1869-1940), foi enviada para a ilha de Príncipe, na costa oeste da África. Já a expedição norte-americana enviada a Sobral, composta pelo meteorologista Andrew Thomson (1893-1974) e pelo geofísico Daniel Wise, tinha como objetivo realizar observações sobre eletricidade atmosférica e magnetismo terrestre durante o eclipse (Crispino, Lima, 2018).

A expedição do ON era chefiada por Morize e composta pelos astrônomos Domingos da Costa (1882-1956) e Allyrio de Mattos (1889-1975), pelo “calculador" Lelio Gama (18921981), pelo meteorologista Luís Rodrigues e pelo mecânico Arthur Almeida. Também integravam a expedição o químico Theophilo Lee (1873-1926), do Serviço Geológico, e um carpinteiro, Primo Flores (Mourão, 2003, p.119-120). O objetivo da expedição brasileira era fotografar a coroa solar e fazer uma análise espectroscópica de sua composição.

\section{A coleção brasileira de negativos de vidro do eclipse em Sobral}

A coleção de placas de vidro da expedição brasileira enviada a Sobral em 1919 integra a Seção de Obras Raras da Biblioteca do ON. A origem dessa biblioteca remonta à década de 1840, início do funcionamento efetivo do ON, ainda ligado à Escola Militar. A biblioteca foi algumas vezes transportada e reinstalada, conforme o observatório tinha sua sede 
transferida, primeiro para o morro do Castelo, depois para o campus do morro de São Januário, onde ainda hoje se localiza. Em 1990, durante reorganização da biblioteca, foi decidido que os livros publicados até 1930 seriam separados do restante do acervo, o que deu origem à Seção de Obras Raras. Em levantamento divulgado em 2018, esta contabilizava cerca de dois mil volumes, entre livros e periódicos, seiscentas fotografias em papel e mil fotografias em placas de vidro (incluindo negativos e positivos) (Morize, 1987; Tavares, Santos, Videira, 1997; Silva Júnior, 2018).

Em meados da década de 1990 houve a primeira grande iniciativa de identificação, higienização, duplicação e recondicionamento da coleção de placas de vidro da biblioteca, realizada por meio de uma cooperação entre o Observatório e o Centro de Conservação e Preservação Fotográfica da Fundação Nacional de Artes (CCPF/Funarte). Na época, porém, com algumas exceções, as placas de vidro relativas à expedição brasileira enviada a Sobral não foram tratadas. Isso só seria feito a partir de 2016, com a aproximação do centenário do evento. A mais recente iniciativa visava, sobretudo, à digitalização desse material, a fim de evitar o manuseio dos originais e permitir o acesso a um público mais amplo (Veiga et al., 2015).

A coleção de Sobral possui cerca de 120 fotografias, das quais metade classificamos, em nosso trabalho, como "astronômicas". Nessa categoria estão incluídas imagens do disco do Sol, da coroa solar, de uma protuberância solar e de espectros de luz (todas originalmente em preto e branco). Além disso, a coleção possui fotografias genericamente classificadas na página da instituição (Observatório Nacional, 2017) como "cotidiano", as quais consistem em imagens dos astrônomos (Figura 1), dos instrumentos e do acampamento brasileiro em Sobral, na praça do Patrocínio (Figura 2). É provável que estas últimas sejam de autoria de Morize, astrônomo particularmente interessado na fotografia e seus processos. Na lista de equipamentos levados a Sobral constam duas câmeras fotográficas avulsas, sem especificações mais detalhadas.

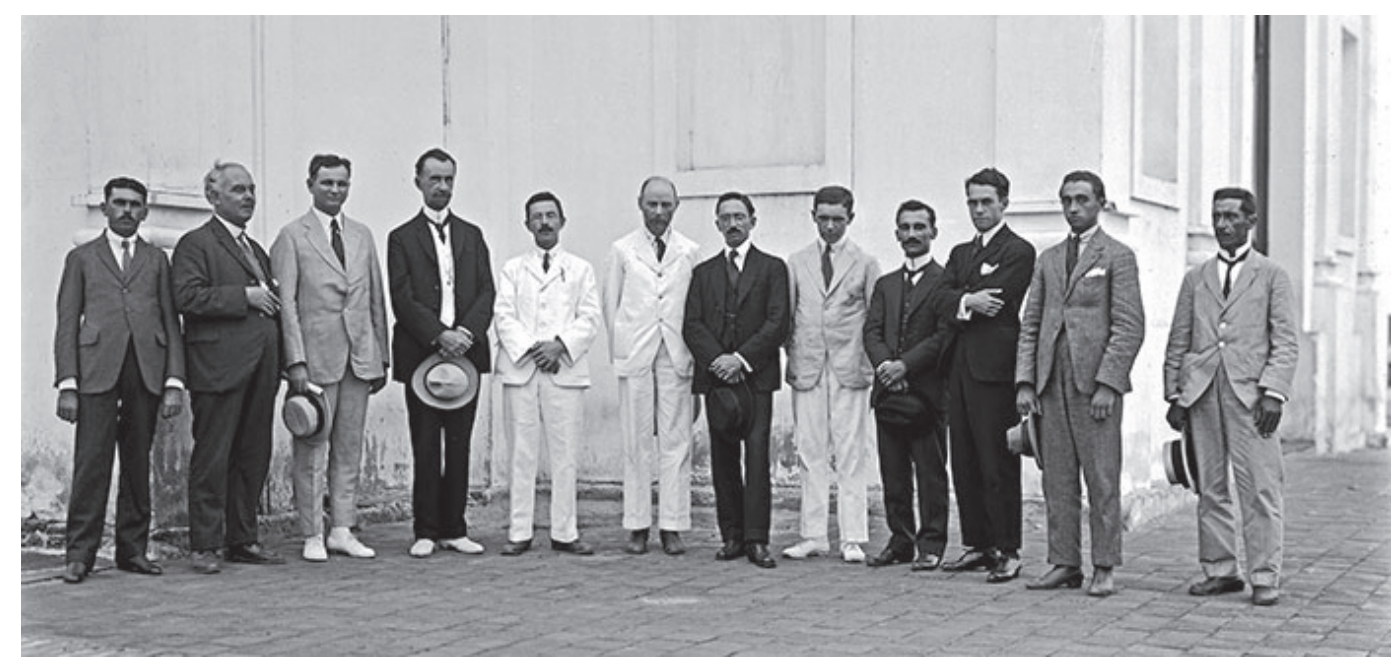

Figura 1: Membros das expedições reunidas em Sobral para observação do eclipse total de Sol de 29 de maio de 1919. Da esquerda para a direita, os brasileiros são Luiz Rodrigues $\left(1^{\circ}\right)$, Theophilo Lee $\left(2^{\circ}\right)$, Henrique Morize $\left(4^{\circ}\right)$, Allyrio de Mattos $\left(7^{\circ}\right)$, Domingos da Costa $\left(9^{\circ}\right)$ e Lelio Gama $\left(10^{\circ}\right)$; os ingleses são Charles Davidson ( $\left.5^{\circ}\right)$ e Andrew Crommelin $\left(6^{\circ}\right)$; e os norte-americanos, Daniel Wise ( $3^{\circ}$ ) e Andrew Thomson ( $8^{\circ}$ ) (Biblioteca do Observatório Nacional, placa EclP0021) 


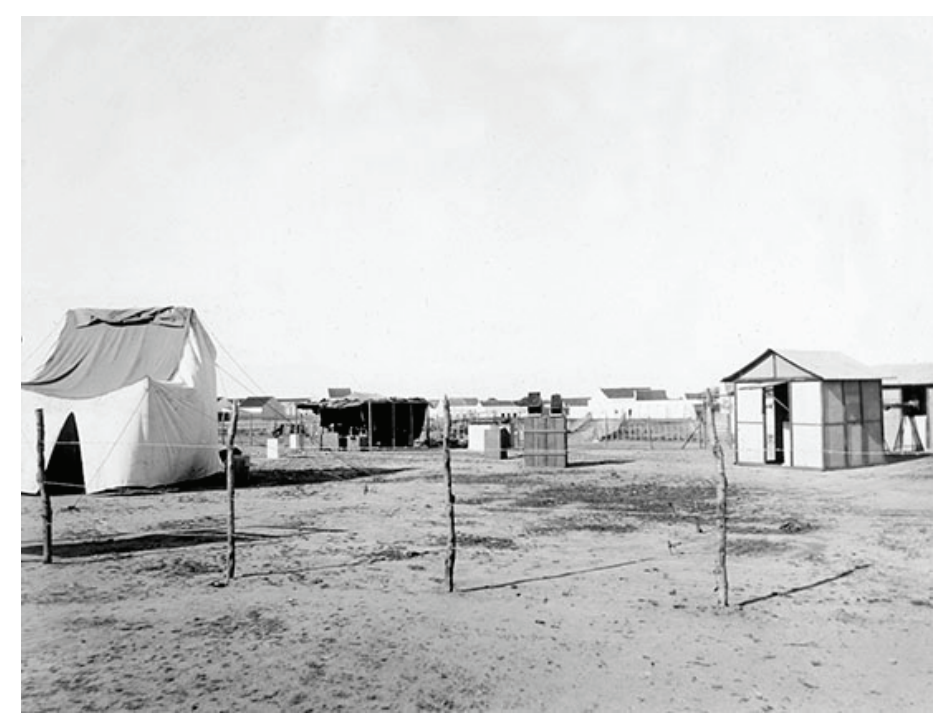

Figura 2: Observatório provisório instalado pela expedição brasileira na praça do Patrocínio, em Sobral. À direita da imagem, veem-se duas tendas pré-montadas interligadas por um tubo. Trata-se do aparato concebido para proteger a imensa luneta de Mailhat (de 8 metros) e seus acessórios (a câmera fotográfica e o celostato), da chuva e da poeira. A tenda de lona clara, à esquerda, abriga a luneta menor, de Steinheil. No fundo da imagem, sob uma lona de cor escura, estão abrigados os três espectrógrafos (Biblioteca do Observatório Nacional, placa EcIP0025)

Conforme os padrões de objetividade científica da época, a expedição brasileira se preparou para obter séries de fotografias astronômicas, e para isso levou a Sobral diversos equipamentos. Os espectros deveriam ser captados com o auxílio de três espectrógrafos de Hilger, cada um deles acoplado a câmeras fotográficas, sendo que com o maior deles seria possível obter espectros de $3 \times 10$ polegadas $(8 \mathrm{~cm} \times 25 \mathrm{~cm})$. Os outros dois eram menores, normalmente usados em laboratório. Costa e Lee ficaram encarregados da operação dos três equipamentos, como informa Morize (1920, p.74) no "Relatório dos resultados do eclipse" apresentado na Academia Brasileira de Ciências (ABC) e publicado em sua revista.

Porém, segundo Morize, não foram obtidas fotografias do espectro da coroa com o grande espectrógrafo. De fato, os 23 negativos de vidro contendo espectros na coleção atribuída a Sobral possuem dimensões menores, de $8 \mathrm{~cm}$ x $10 \mathrm{~cm}$. Aliás, nem é possível afirmar que todos tenham sido obtidos na ocasião, já que pelo menos dois deles trazem anotadas à mão, na própria placa de vidro, datas diferentes: "janeiro 31" e "17 setembro 1919" (Figura 3). Em seu relatório, Morize não informa quantas fotografias foram tiradas durante o eclipse, mas menciona que só dois negativos possuíam a nitidez necessária à realização de medições com o objetivo de determinar o comprimento de onda de elementos químicos. Os cálculos feitos não foram divulgados em periódicos científicos, constam apenas em anotações manuscritas hoje depositadas no Arquivo de História da Ciência do Museu de Astronomia e Ciências Afins (AHC/Mast). 


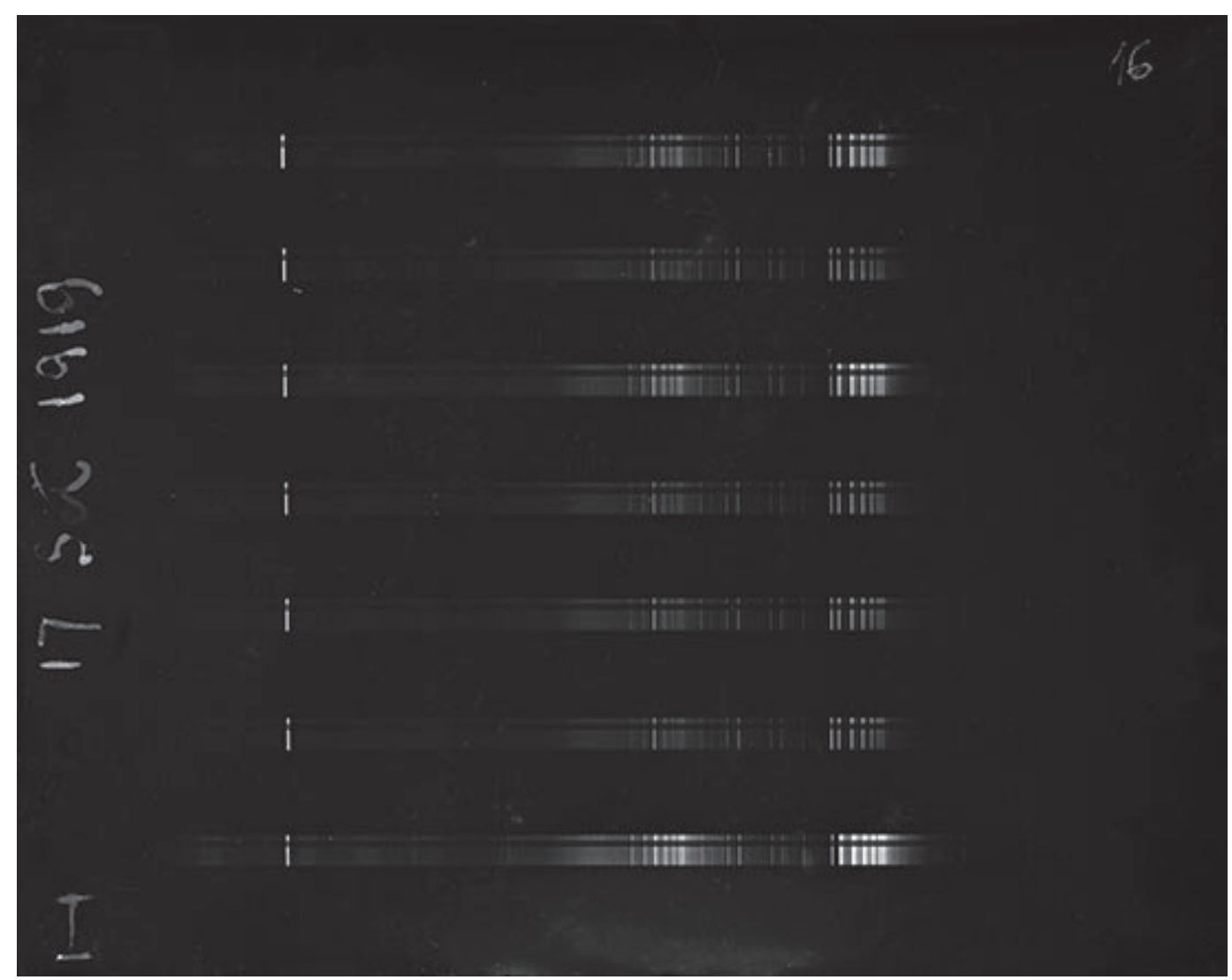

Figura 3: Placa de vidro de $8 \mathrm{~cm} \times 10 \mathrm{~cm}$ contendo negativo de uma fotografia espectroscópica do Sol originalmente armazenada junto à coleção de Sobral, porém com data de 17 de setembro de 1919, posterior ao período em que os astrônomos do ON permaneceram na cidade (Biblioteca do Observatório Nacional, placa Ecl0085)

Duas lunetas astronômicas foram levadas a Sobral com o objetivo de obter fotografias da coroa solar. Ambas foram adquiridas/reformadas para a observação do eclipse de 1912, porém não foram utilizadas naquela ocasião devido à chuva. A maior delas, da fabricante Mailhat, possuía $15 \mathrm{~cm}$ de abertura e $8 \mathrm{~m}$ de distância focal, e foi instalada junto a um celostato também da Mailhat (para redirecionar os raios solares em direção à luneta, instalada em posição fixa na horizontal) e acoplada a uma câmera fotográfica. O formato das placas fotográficas obtidas com esse instrumento era de $18 \mathrm{~cm} \times 24 \mathrm{~cm}$, conforme informação apresentada por Morize (1920, p.71) em seu relatório. A luneta de Mailhat ficou a cargo de Mattos. Com ela foram tiradas oito fotografias durante a totalidade do eclipse, com exposições diferentes, sendo que uma delas com resultado ruim (Mourão, 2003, p.132). 


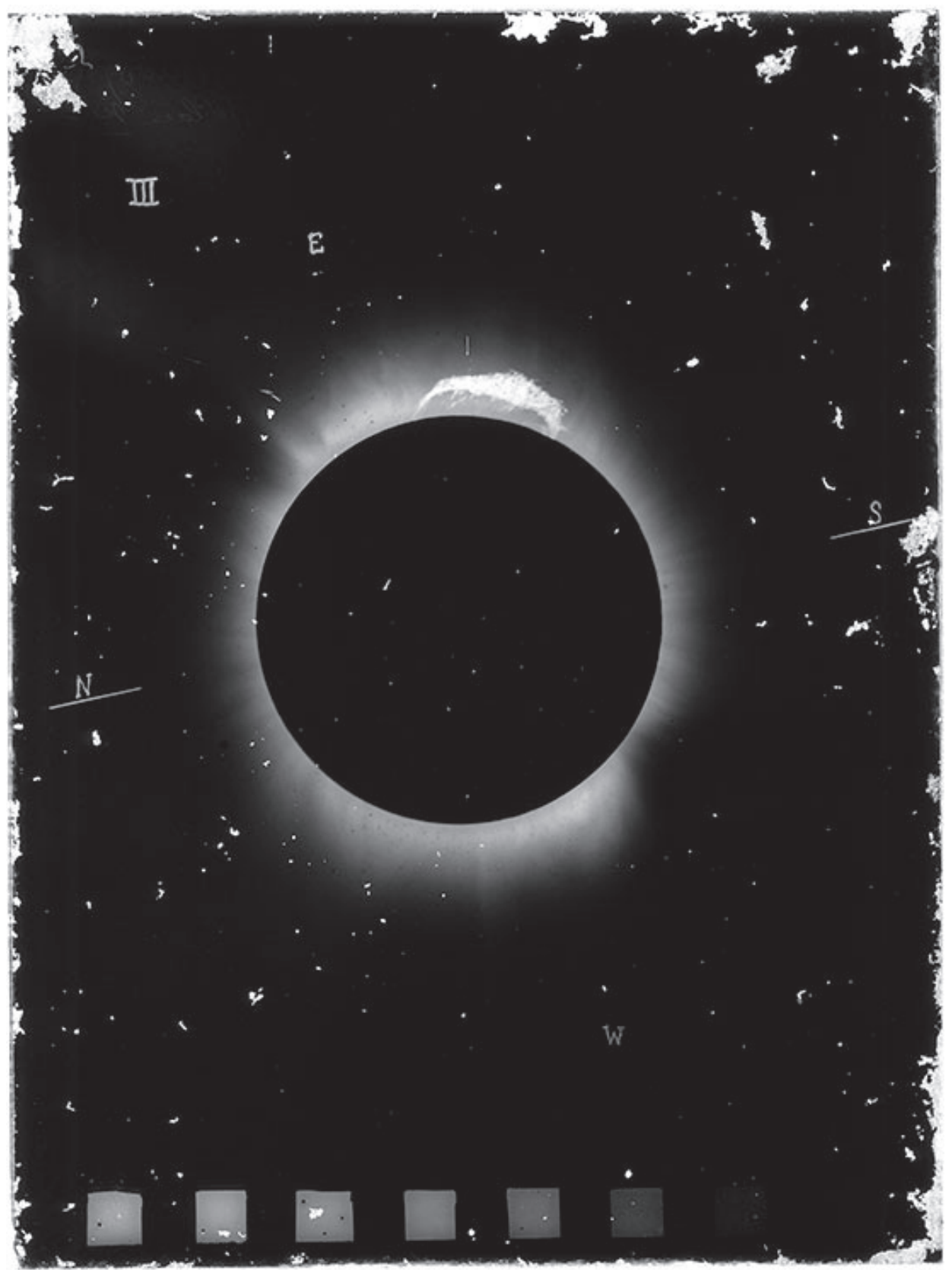

Figura 4: Placa de vidro de $18 \mathrm{~cm} \times 24 \mathrm{~cm}$ contendo imagem positiva da coroa solar obtida pela luneta de Mailhat, com tempo de exposição supostamente de dois segundos, onde se destaca a grande protuberância. As marcações na parte inferior da fotografia foram feitas antes do eclipse, com diferentes tempos de exposição e o auxílio de uma lâmpada, para fins de fotometria. Nota-se acentuada perda de emulsão nas bordas e em diversos pontos da fotografia (Biblioteca do Observatório Nacional, placa Ecl0038) 


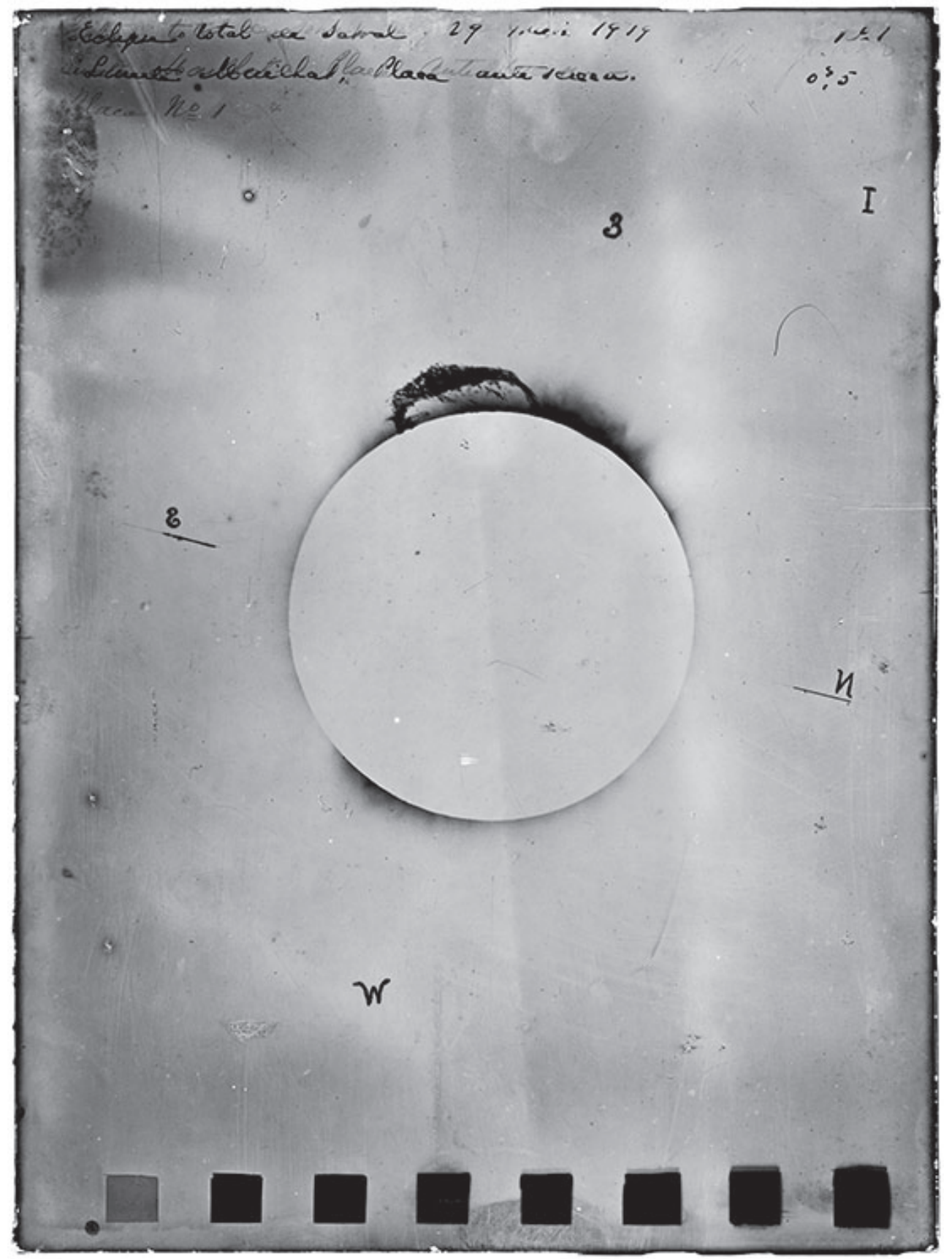

Figura 5: Placa de vidro de $18 \mathrm{~cm} \times 24 \mathrm{~cm}$ com imagem negativa da coroa solar, obtida pela luneta de Mailhat. No alto da imagem é possível ler "Eclipse total de Sobral - 29 maio 1919 - Luneta Mailhat - placa ante screen - 0,5s". No alto, à direita, o número de identificação "I" indica que essa foi a primeira e a menor exposição (Biblioteca do Observatório Nacional, placa Ecl0033) 
Ora, no conjunto de Sobral existem 17 placas de vidro com $18 \mathrm{~cm}$ x $24 \mathrm{~cm}$ que registram imagens astronômicas. Ao analisar esse conjunto foi possível identificar apenas seis negativos diferentes da coroa solar com anotações feitas à mão na própria placa, onde constam referências à luneta de Mailhat e aos seguintes tempos de exposição: "0,5s", "1s ", "4s", "6$8 s$ ", "[il.]-12s", e "20s". As placas possuem ainda, anotada à mão, uma numeração sequencial em algarismos romanos, de I a VIII, que também ajudou na identificação. Como não consta a placa $V$ na coleção, pode-se inferir daí que essa tenha sido a fotografia considerada ruim, sendo portanto descartada. Além disso, não consta o negativo III, provavelmente a exposição intermediária entre um e quatro segundos, tendo restado apenas o respectivo positivo (Figura 4). Em contrapartida, existem dois negativos de número I (Figura 5), um deles certamente de segunda geração. Todas as demais placas são cópias positivas dos sete negativos originais. Em várias fotografias é possível ver em destaque uma protuberância solar. De acordo com o relatório de Morize, obter a fotografia de uma protuberância solar era um desafio na época, e a imagem feita por Mattos com a luneta de Mailhat em uma exposição muito curta foi elogiada por Perrine, veterano em fotografias de eclipses totais do Sol:

As fotografias com curta exposição mostram a SE do Sol a linha da protuberância de que já falei. A seu respeito consultei uma das maiores autoridades mundiais em assuntos de eclipses, o prof. Ch. Perrine, atual diretor do Observatório de Córdoba, na República Argentina ... Enviei-lhe algumas das nossas fotografias e tive a satisfação de saber que foram consideradas 'esplêndidas', e que a protuberância nelas retratada era admirável (Morize, 1920, p.77; destaque no original).

A comissão brasileira levou outra luneta fotográfica menor, com $10 \mathrm{~cm}$ de abertura e 1,5m de distância focal, da fabricante Steinheil. Essa luneta foi montada sobre uma coluna de madeira, onde se apoiava o mecanismo de relojoaria que permitia que o instrumento, apontado para o Sol, se movimentasse durante os cerca de cinco minutos da totalidade do eclipse, compensando a rotação da Terra. As placas fotográficas com ela obtidas tinham o formato de $9 \mathrm{~cm} \times 12 \mathrm{~cm}$. Apenas em seu diário de viagem Morize deixa claro que esse instrumento foi operado por ele, ao explicar que, devido ao mau funcionamento tanto do obturador quanto do mecanismo de relojoaria, só pôde fazer seis fotografias, das quais uma antes da totalidade do eclipse:

Por causa de tudo isso apenas pude fazer seis clichês dos quais um antes da totalidade, para fixar a orientação da placa ... À noite revelei as placas, obtendo dois bons clichês, um sofrível e dois meios [meio sofríveis] devido ao mau funcionamento do obturador e do movimento de relojoaria e o céu [sic] ter ficado ainda exposto quando reapareceu o Sol (Morize citado em Mourão, 2003, p.131).

Na coleção de placas de vidro de Sobral há apenas cinco negativos com $9 \mathrm{~cm} \times 12 \mathrm{~cm}$, todos com imagens da coroa solar. De fato, desse pequeno conjunto, apenas duas são nítidas (Figura 6), estando as outras duas bastante desfocadas (Figura 7) e uma com superexposição acentuada (Figura 8). Até a finalização da pesquisa que deu origem a este artigo, não havia identificação e atribuição de autoria a esse material tanto nos registros na Biblioteca do Observatório como na página institucional com as cópias digitalizadas das placas de vidro de Sobral, e tampouco na literatura especializada. 


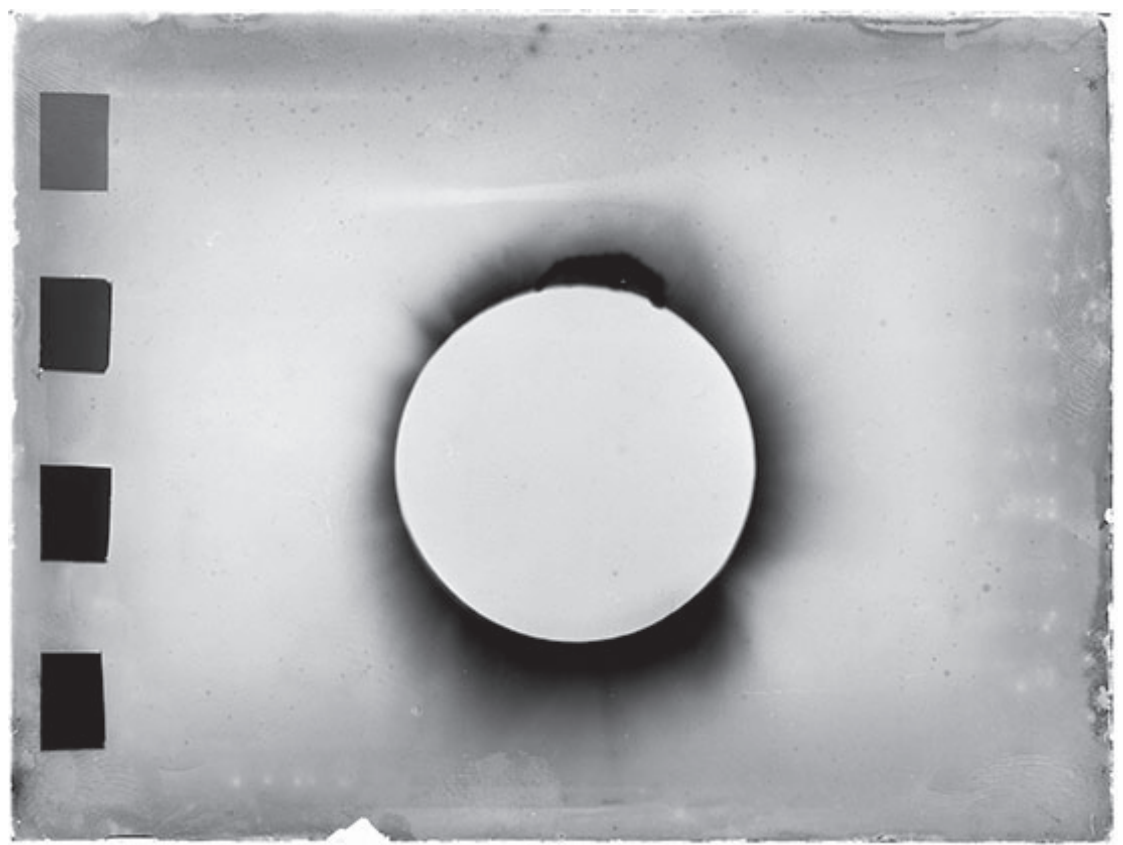

Figura 6: Placa de vidro de $9 \mathrm{~cm} \times 12 \mathrm{~cm}$ contendo negativo de fotografia da coroa solar obtida por Henrique Morize com a luneta de Steinheil. A despeito de vários problemas apresentados pelo instrumento, Morize conseguiu aproveitar os $5 \mathrm{~m} 12 \mathrm{~s}$ da fase da totalidade para obter duas boas fotografias da coroa solar, inéditas em sua carreira. Morize observou os eclipses de 1893 e 1912, mas em nenhuma dessas ocasiões conseguiu fotografar o fenômeno (Biblioteca do Observatório Nacional, placa Ecl0054)

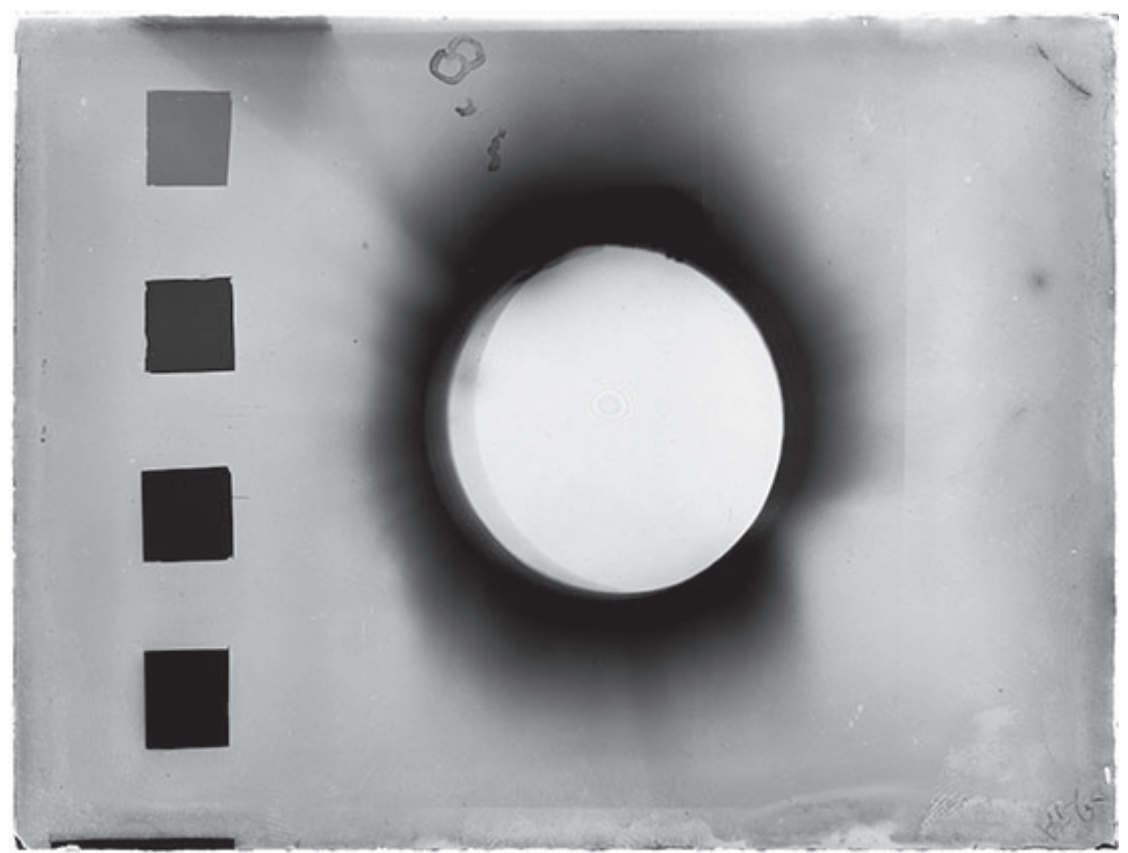

Figura 7: Fotografia desfocada da coroa solar obtida por Henrique Morize com a luneta de Steinheil. O problema foi causado por irregularidades no mecanismo de relojoaria do instrumento, cuja função é mantê-lo alinhado à direção dos raios luminosos (Biblioteca do Observatório Nacional, placa Ecl0054) 


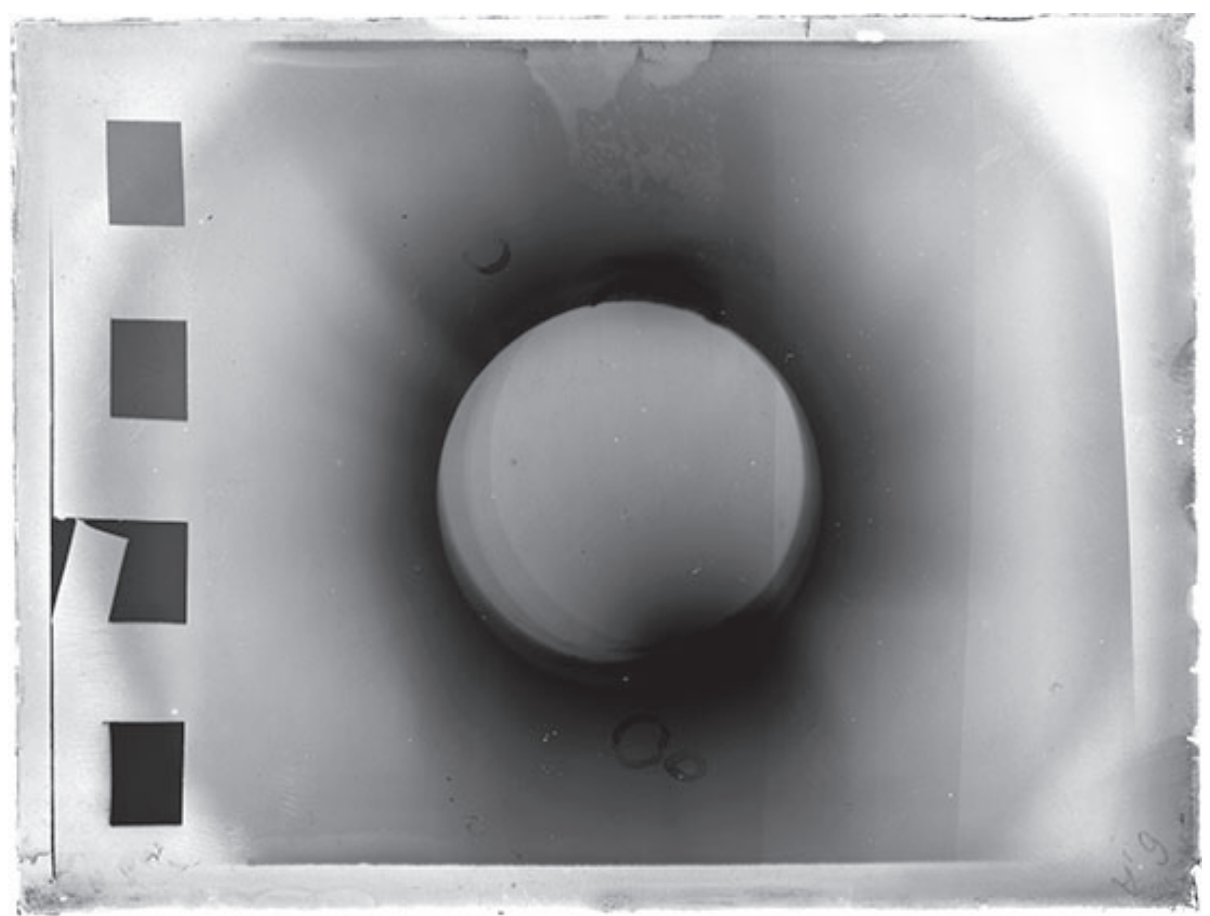

Figura 8: Fotografia da coroa solar, obtida por Henrique Morize com a luneta de Steinheil, com superexposição. O problema foi causado por defeito na tampa (ou obturador) do chassi onde eram inseridas as placas de vidro emulsionadas (Biblioteca do Observatório Nacional, placa Ecl0054)

A esse respeito, é importante notar que a expedição a Sobral foi a terceira de que Morize participou com o objetivo de fotografar um eclipse total do Sol. Por ocasião do eclipse de 16 de abril de 1893, quando foi enviado pelo ON ao litoral do Ceará, onde o fenômeno seria visível, o então jovem astrônomo já era entusiasta da fotografia. Durante a Comissão Exploradora do Planalto Central do Brasil, encerrada pouco antes, em fevereiro de 1893, tirou inúmeras fotos das paisagens e da expedição em si, muitas delas ainda inéditas (Costa, 2012). Não existem, contudo, registros ou cópias de fotografias astronômicas eventualmente obtidas por Morize em seu primeiro eclipse. Uma explicação possível encontra-se em um telegrama no qual ele afirma que o eclipse teria sido "observado [em] medíocres condições" (Barboza, 2010, p.280). Naquela época e também posteriormente, diversas vezes Morize trabalhou em colaboração com Marc Ferrez (1843-1923), um dos mais importantes nomes da fotografia profissional brasileira na virada do século XX, como em suas experiências pioneiras com o raio X, feitas em 1896 e 1897 (Videira, 2003). Talvez por causa das sólidas relações profissionais e pessoais estabelecidas entre ambos, Ferrez inclusive estava com Morize na observação do eclipse de 1912 em Passa Quatro, quando o astrônomo tentou pela segunda vez fotografar um eclipse - sem sucesso. Assim, apesar dos problemas relatados em 1919, foi apenas nessa tentativa que o astrônomo teve sucesso na obtenção de suas próprias fotografias da coroa solar.

Outro material iconográfico interessante identificado durante a pesquisa foram os diversos slides preparados por Morize para a apresentação de seu relatório à ABC. A 
conferência foi realizada às $20 \mathrm{~h} 30$ do dia 26 de fevereiro de 1920, uma quinta-feira, na sala da congregação da Escola Politécnica, no largo de São Francisco, conforme noticiaram os jornais na época (Conferências, 1920, p.5).

Esse subconjunto da coleção de placas de vidro de Sobral perfaz o total de 17 objetos, sendo que, embora essas imagens não sejam de todo inéditas, uma vez que muitas foram reproduzidas na versão impressa do relatório publicada na Revista de Sciencias, ainda não haviam recebido a atenção e o devido destaque entre os profissionais da preservação e os historiadores. Os slides têm a dimensão de $8 \mathrm{~cm}$ x $10 \mathrm{~cm}$ e são constituídos por duas placas finas de vidro unidas por uma moldura comum, revestida com fita de papel tipo crepom na cor preta. A maioria dos slides mostra imagens da coroa solar. Em alguns casos foi utilizado papel tipo cartão preto colado entre as faces, como um passe-partout. Em outros, papelcartão preto também foi colado sobre o disco solar, provavelmente para realçar o efeito da imagem da coroa (Figura 9). E para realçar a imagem da protuberância solar foram usadas duas técnicas diferentes: o colorido artificial na própria imagem positiva (Figura 9) e vidro vermelho (Figura 10). ${ }^{2}$

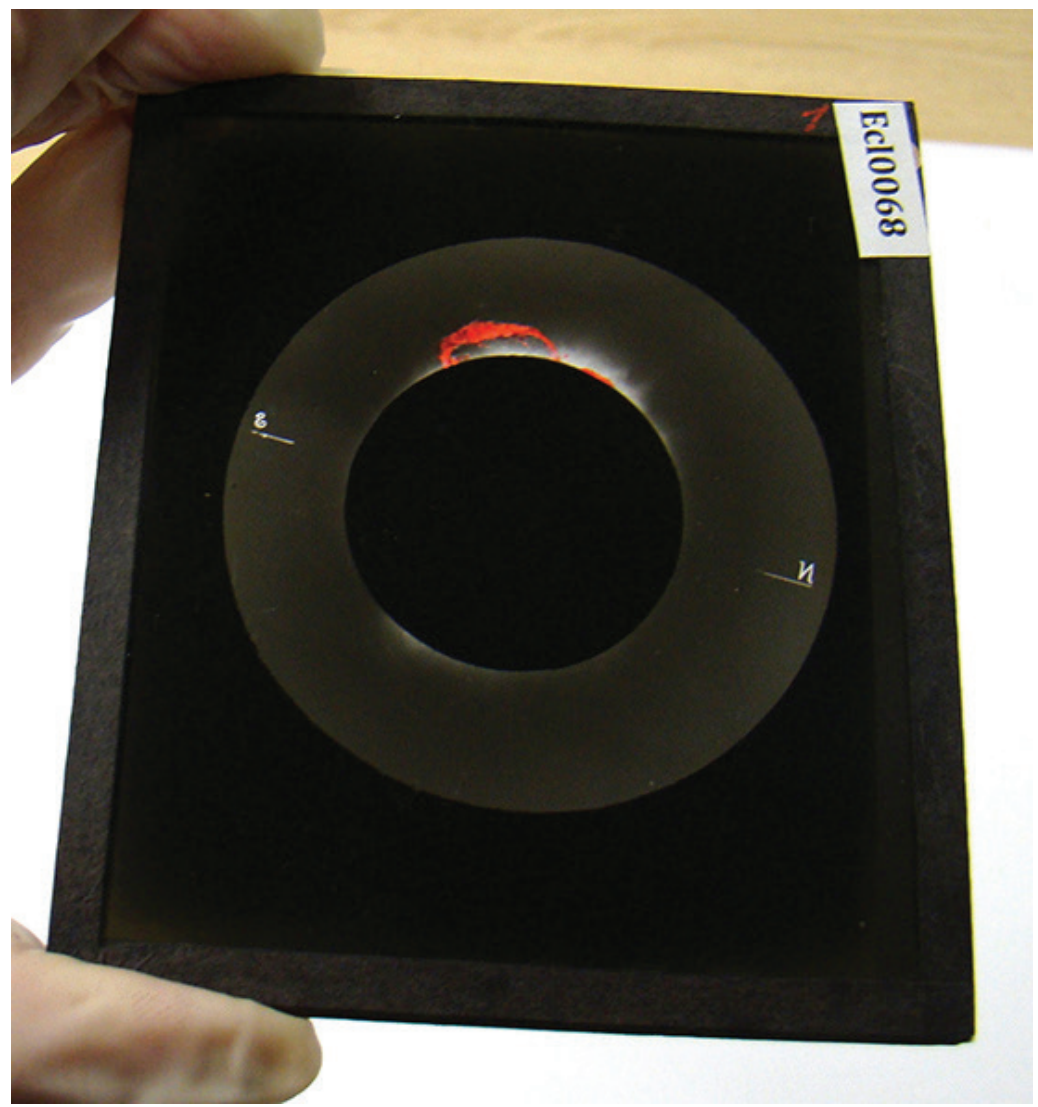

Figura 9: Diapositivo da coroa solar preparado, provavelmente, para a palestra proferida por Morize na Academia Brasileira de Ciências, a respeito da participação brasileira na observação do eclipse do Sol de maio de 1919. É possível distinguir a utilização de papel-cartão preto cobrindo a parte externa da imagem original e o disco do Sol, e o uso de colorido artificial na cor vermelha para destacar a imagem da protuberância solar. A fotografia original foi obtida com a luneta de Mailhat, por Allyrio de Mattos (Biblioteca do Observatório Nacional, placa Ecl0068) 


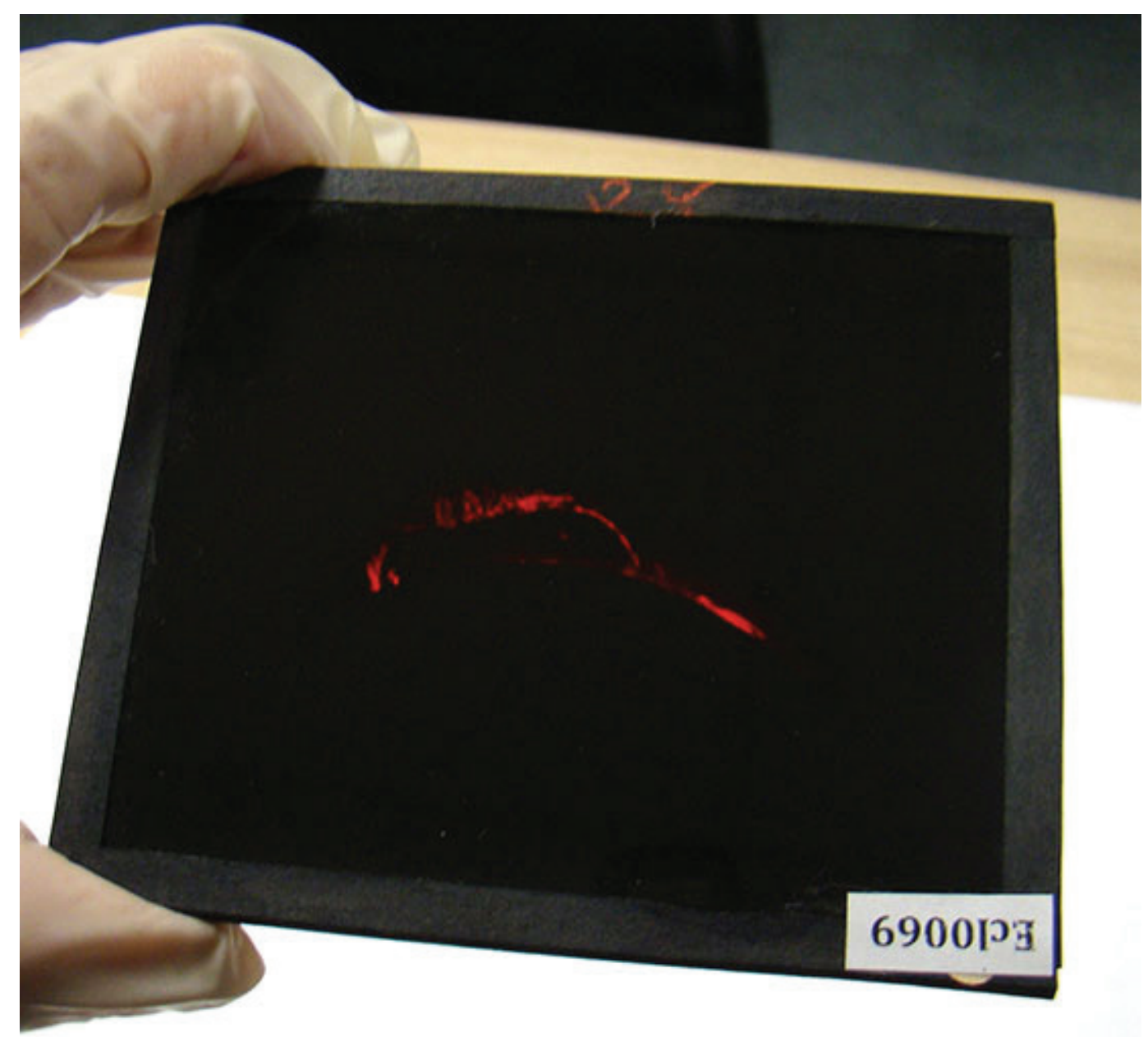

Figura 10: Diapositivo da coroa solar preparado para apresentação de Morize na Academia Brasileira de Ciências, onde foram utilizados vidros vermelhos para destacar a imagem da protuberância solar (Biblioteca do Observatório Nacional, placa Ecl0069)

A conferência de 1920 não foi a primeira em que Morize se valeu do recurso de projetar diapositivos para reforçar sua argumentação oral e entreter a plateia. Em palestra proferida em 4 de outubro de 1917, também na Escola Politécnica, Morize já havia projetado slides com "mapas do tempo" para demonstrar a possibilidade de se determinar a trajetória das tempestades e defender a criação de um serviço de previsão do tempo no Brasil (Barboza, 2006). Conforme apontou a historiografia das ciências, além de físico, astrônomo, meteorologista e fotógrafo, Morize foi pioneiro na divulgação científica no Brasil (Massarani, 1998; Videira, 2003).

\section{Considerações finais}

A fotografia tornou-se a principal forma de obtenção de dados observacionais na astronomia a partir do final do século XIX, com a consolidação da astrofísica. Apesar do desenvolvimento 
de novos materiais e processos fotográficos desde então, como os negativos de nitrato de celulose, a utilização de placas de vidro na astronomia estendeu-se até o final dos anos 1980, devido à sua maior estabilidade. Esse tipo de suporte só foi substituído quando surgiram os chamados CCD (charge coupled device), que convertem a luz em código digital e assim conferem precisão algorítmica às imagens resultantes. Em decorrência desse viés disciplinar, levantamento realizado no início do século XXI estimou que existem de dois a três milhões de placas de vidro espalhadas em observatórios de todo o mundo (Kroll, Bräuer, 2000).

A coleção de fotografias astronômicas feitas pela expedição brasileira enviada a Sobral há pouco mais de cem anos, em maio de 1919, representa uma pequena fração da volumosa coleção de placas de vidro do Observatório Nacional. Boa parte das placas analisadas durante nossa pesquisa apresentava avançado grau de deterioração, como espelhamento, perda de emulsão e fraturas. Graças à popularidade de Einstein e da teoria da relatividade, não só esse conjunto, mas toda a coleção do ON foi digitalizada, o que representa uma etapa fundamental em qualquer projeto de preservação de acervos científicos. Cabe aos historiadores das ciências cumprir outra etapa igualmente fundamental: a incorporação desse material entre suas fontes de pesquisa. Com esse artigo, esperamos ter contribuído nessa direção.

\section{AGRADECIMENTOS}

Os autores agradecem a Carlos Veiga e Kátia dos Santos, profissionais do Observatório Nacional, pelo acesso ao material iconográfico. Agradecem também a todos os pesquisadores que contribuíram para a elaboração desse artigo, com informações, críticas e sugestões, como Alda Heizer, Sandra Baruki, Laís Tavares e um parecerista não identificado.

\section{NOTA}

${ }^{1}$ Quando o artigo foi enviado para publicação, a maioria das fotos era inédita e só acessível a consulta in situ, mediante autorização especial. Muitas ainda permanecem inéditas em artigos científicos e de divulgação; no entanto, desde maio de 2019, cópias digitalizadas de todas elas estão disponíveis na internet, no site do Observatório Nacional: <https://daed.on.br/sobral/>.

2 [Nota do editor] Imagem colorida disponível em: <www.scielo.br/hcsm>.

\section{REFERÊNCIAS}

BARBOZA, Christina Helena.

Ciência e natureza nas expedições astronômicas para o Brasil (1850-1920). Boletim do Museu Paraense Emílio Goeldi. Ciências Humanas, v.5, n.2, p.273-294. 2010.

BARBOZA, Christina Helena.

História da meteorologia no Brasil (1887-1917). In: Congresso Brasileiro de Meteorologia, 14., 2006, São Paulo. Anais... São Paulo: Sociedade Brasileira de Meteorologia. Disponível em: <http://www.cbmet.com/cbm-files/14-83a040e3 a3a6b837e3cdae3619732c01.pdf >. Acesso em: 8 abr. 2014. 2006.

BIGG, Charlotte.

Photography and labour history of astrometry: the Carte du Ciel. In: Hentschel, Klaus; Wittmann,
Axel (Ed.). The role of visual representations in astronomy: history and research practice. Frankfurt: Harri Deutsch. p.90-106. 2000.

CAFFARELLI, Roberto Vergara.

O eclipse solar de 1912. Ciência e Cultura, v.32, n.5, p.561-573. 1980.

CONFERÊNCIAS.

Conferências. O Paiz, n.12.925, p.5. 29 fev. 1920.

COSTA, Bianca Mandarino.

Fotografias da Comissão Cruls: uma análise da imagem. In: Silva, Maria Celina S. de Mello; Barboza, Christina Helena (Org.). Acervos de ciência e tecnologia no Brasil: preservação, história e divulgação. Rio de Janeiro: Museu de Astronomia e Ciências Afins. p.27-78. 2012. 
CRISPINO, Luís Carlos; LIMA, Marcelo Costa de. Expedição norte-americana e iconografia inédita de Sobral em 1919. Revista Brasileira de Ensino de Física, v.40, n.1, p.1-8. 2018.

DASTON, Lorraine.

Uma história da objetividade científica. In: Daston, Lorraine; Almeida, Tiago Santos (Org.). Historicidade e objetividade. São Paulo: Liber Ars. p.69-78. 2017.

DASTON, Lorraine; GALISON, Peter. The image of objectivity. Representations, n.40, p.81-128. 1992.

EINSENSTAEDT, Jean; VIDEIRA, Antonio Augusto Passos.

A relatividade geral verificada: o eclipse de Sobral de 29/05/1919. In: Moreira, Ildeu de Castro; Videira, Antonio Augusto Passos (Org.). Einstein e o Brasil. Rio de Janeiro: Editora da UFRJ. p.77-99. 1995.

KENNEFICK, Daniel.

Testing relativity from the 1919 eclipse: a question of bias. Physics Today, v.62, n.3, p.3742. 2009.

KROLL, Peter; BRÄUER, Hans-Jürgen. Working in a gold mine: archival wide-field plates. Acta Historical Astronomiae, v.9, p.136-145. 2000.

LANKFORD, John.

The impact of photography on astronomy. In: Gingerich, Owen (Ed.). Astrophysics and twentieth-century astronomy to 1950: part A. Cambridge: Cambridge University Press. p.1639. 1984.

LATOUR, Bruno.

Ciência em ação: como seguir cientistas e engenheiros sociedade afora. São Paulo: Editora da Unesp. 2000.

MASSARANI, Luisa.

A divulgação científica no Rio de Janeiro: algumas reflexões sobre a década de 20 . Dissertação (Mestrado) - Universidade Federal do Rio de Janeiro, Rio de Janeiro. 1998.

MEADOWS, Arthur Jack.

The new astronomy. In: Gingerich, Owen (Ed.). Astrophysics and twentieth-century astronomy to 1950: part A. Cambridge: Cambridge University Press. p.59-72. 1984a.

MEADOWS, Arthur Jack.

The origins of astrophysics. In: Gingerich, Owen (Ed.). Astrophysics and twentiethcentury astronomy to 1950: part A. Cambridge: Cambridge University Press. p.3-15. 1984b.
MORIZE, Henrique.

Observatório Astronômico: um século de história (1827-1927). Rio de Janeiro: Museu de Astronomia e Ciências Afins; Salamandra. 1987.

MORIZE, Henrique.

Resultados obtidos pela Comissão Brasileira do Eclipse de 29/05/1919. Revista de Sciencias, v.4, n.3, p.65-81. 1920.

MOURÃO, Ronaldo Rogério de Freitas.

Einstein: de Sobral para o mundo. Sobral: UVA. 2003.

NEVES, Margarida.

As vitrines do progresso. Rio de Janeiro: PUC-Rio; Finep; CNPq. 1986.

OBSERVATÓRIO NACIONAL.

Eclipse de Sobral. Página inicial. Disponível em: <https://daed.on.br/sobral/>. Acesso em: 2 dez. 2019. 2017.

PANG, Alex Soojung-Kim.

Empire and the Sun: Victorian solar eclipse expeditions. Stanford: Stanford University Press. 2002.

PERES, Isabel Marília.

Processos fotográficos históricos. In: Costa, Fernanda Madalena; Jardim, Maria Estela (Org.). 100 anos de fotografia científica em Portugal (18391939). Lisboa: Edições 70. p.17-34. 2014.

ROUILLÉ, André.

A fotografia: entre documento e arte contemporânea. São Paulo: Editora Senac. 2009.

SILVA JÚNIOR, Renaldo Nicácio da.

História e memória de vidro: preservação das fotografias brasileiras do eclipse de Sobral.

Dissertação (Mestrado Profissional em

Preservação de Acervos de Ciência e Tecnologia)

- Museu de Astronomia e Ciências Afins, Rio de Janeiro. 2018.

TAVARES, Laís; SANTOS, Kátia; VIDEIRA, Antônio Augusto.

A seção de obras antigas da Biblioteca do Observatório Nacional: sua origem e seu estado atual. Rio de Janeiro: Observatório Nacional (Série Ciência e Memória, n.12/1997). 1997.

THOMAS, Ann (Org.).

Beauty of another order: photography in science. New Haven: Yale University Press. 1998.

TURAZZI, Maria Inez.

$\mathrm{O}$ 'homem de invenções' e as 'recompensas nacionais': notas sobre H. Florence e L.J.M. Daguerre. Anais do Museu Paulista, v.16, n.2, p.11-46. 2008. 
VEIGA, Carlos et al.

Placas fotográficas do eclipse de Sobral:

Observatório Nacional preserva memória de um dos eventos mais importantes da ciência. Ciência Hoje, v.56, n.331, p.34-39. 2015.
VIDEIRA, Antonio Augusto Passos.

Henrique Morize e o ideal de ciência pura na República Velha. Rio de Janeiro: Editora FGV. 2003.

$\rightarrow \rightarrow \rightarrow<<$ 